\title{
Hipermobilidade Estética e Dispositivos de Controle de Circulação: o Desejo de Ser Notado e Encontrado na Internet
}

\author{
Hypermobility Aesthetics and Devices for Controlling the \\ Circulation: the Desire to Be Noticed and Found on the Internet
}

\author{
Cristian Caê Seemann Stassun ${ }^{1}$, Selvino José Assmann ${ }^{2}$
}

\begin{abstract}
Resumo
Este artigo problematiza a forma com que os sujeitos que possuem acesso à Internet pelo computador ou por meio de dispositivos móveis socializam suas informações pessoais, fotos e, recentemente, códigos de localização remota. Exploramos o uso dessas tecnologias tentando entender como os usuários fazem de suas vidas uma estetização de personagens através de uma espetacularização da intimidade pela Internet. Essa exposição sensível faz com que os deslocamentos pela Web figurem uma hipermobilidade sem fronteiras que estreitam as noções de espaço-tempo, com relações instantâneas e de alcance global. Em contato com o sujeito, estratégias de marketing balizam dispositivos de controle de circulação, ferramentas de redes sociais e resultam em um desejo de ser notado e encontrado no ciberespaço.
\end{abstract}

Palavras-chave: Hipermobilidade. Dispositivo. Internet. Redes Sociais. Riscos.

\begin{abstract}
This article discusses the way that the subjects, who have internet access by computer or through mobile devices, socialize their personal information, pictures and, recently, codes of remote location. It is explored the use of these technologies trying to understand how users turn their lives into characters' aestheticization through intimacy spectacularization on the Internet. This exposure through the web causes significant hypermobility without borders and narrow notions of space-time with instant relations and global reach. In contact with the subject, marketing strategies guide the traffic control devices, social networking tools, and they result in a desire to be noticed and found in the cyberspace.
\end{abstract}

Key words: Hypermobility. Device. Internet. Social networks. Risks.

\footnotetext{
${ }^{1}$ Psicólogo, Especialista em Psicologia Clínica, Mestre em Psicologia, Doutorando Interdisciplinar em Ciências Humanas da UFSC. http://www.cristianstassun.com.br.

2 Professor Doutor da Universidade Federal de Santa Catarina (UFSC) do Programa de PósGraduação Interdisciplinar em Ciências Humanas. E-mail para contato: selvinoas@terra.com.br.
} 


\section{Introdução}

As recentes formas de subjetividade construídas na relação com a Internet e a possibilidade de circulação global, segundo Sassen (1991), formam a maioria das imagens que dominam o cenário sobre a globalização econômica que enfatizou na hipermobilidade e comunicação global a neutralização da noção de lugar e distância. O termo hipermobilidade é um conceito guia que denota, nesses novos perfis dos cidadãos globais, o modo de sua circulação fluida, sem fronteiras e sem custos. $O$ termo aponta para a necessidade de produção de uma capacidade de operação global, coordenação e controle contido em novas tecnologias da informação, no poder das corporações transnacionais e na readaptação das empresas para capturar, com a mesma voracidade, a atenção dos consumidores através de disparos da propaganda.

A noção de cidade global apresenta uma cidade como um contêiner onde habilidades e recursos estão concentrados. Para Sassen (1991), quanto mais uma cidade é capaz de concentrar habilidades e recursos, mais bem-sucedida e poderosa é a cidade, tornando-a suficientemente poderosa para influenciar o que ocorre em torno do mundo. Essa noção, comparada ao fenômeno da relação do sujeito com a Internet, lugar onde encontra todos esses recursos e potencialidades de deslocamento, faz sentido na construção de um significado mais concreto para a capacidade de extensão das relações, desdobramentos de ações e principalmente formação de grupos e redes no espaço virtual criando modelos que influenciam cada vez mais as pessoas.

Acompanhando esse fenômeno de circulação por ambientes Web, novos meios de registro de localização por sites da Internet, redes sociais, celulares e GPS foram criados. Se por um lado muitos optam por circular anônimos por esse cenário, tem-se percebido que redes sociais como o Facebook, Orkut, Youtube, Wordpress, Flickr, Foursquare, Twitter, Google Latitude têm alimentando uma verdadeira espetacularização da intimidade, agora readaptada, onde pessoas mostram imagens de seus corpos, seus pensamentos como expressão de suas individualidades, seu cotidiano remoto através de mensagens de 140 caracteres respondendo o que estão fazendo e principalmente registrando de onde estão falando, qual sua localização atual, sua circulação habitual e seu roteiro de viagens. Fora a preocupação evidente 
que vem a tona nesse contexto, o da segurança pessoal, muitas pessoas não escondem mais seus passos, querem ser notados e são elas mesmas, as produtoras, financiadoras e divulgadoras dos programas que revelam a sua localização.

A problemática que emerge trata de uma hipermobilidade estética dos internautas, seus riscos e produções, buscando responder: de que forma eles se encontram desejando colocar informações íntimas a público? Estão elas sendo atravessadas pela autonomia e auto gerência da técnica? Seria uma nova condição de descontrole pelo consumo da inovação de sistemas de localização? Que nova condição humana é essa que produz subjetividades querendo ser notadas (com fotos, comentários, números de perfis adicionados), encontradas (rastreadas por GPS e divulgando localização) e só conseguindo se sentir alguém quando consumindo as novidades da tecnologia?

Esta pesquisa buscou problematizar os dispositivos de controle de circulação dispostos na Internet e a forma com que os sujeitos transitam por redes Web com uma hipermobilidade estética tal que permitem ter suas informações e intimidade expostas.

\section{Cenário brasileiro do uso de redes sociais}

Existe uma união de fatores que presumem a importância de discutir os primeiros doze anos do século XXI frente ao impacto do uso da Internet e comunicação móvel na população brasileira. Segundo a UIT (União Internacional de Telecomunicações, 2010), as estimativas são que os sinais de celular já cobrem $86 \%$ da população do planeta. De acordo com os dados da Anatel (Agência Nacional de Telecomunicações, 2011), só nos três primeiros meses de 2011 foram registradas 7,6 milhões de novas linhas de telefones celulares, o maior número para o período nos últimos 11 anos. Com isso, o país ultrapassou a marca de 210 milhões de assinantes. Dados da Anatel (2012) indicam que o Brasil fechou janeiro de 2012 com quase 245,2 milhões de linhas ativas na telefonia móvel e tele densidade de 125,29 acessos por 100 habitantes. O número absoluto de novas habilitações (2,9 milhões) é o maior registrado em um mês de janeiro nos últimos 13 anos e representa um crescimento de $1,22 \%$ em relação a dezembro de 2012 . Os terminais $3 G$ (banda larga móvel) totalizaram mais de 50,8 milhões de acessos. 0 
infográfico do Extra (2011), sobre o uso do celular no Brasil, aponta que o número de celular com dados avançados, no uso das funções do celular, já chegam a $40 \%$ (48\% sms e voz, 11\% somente voz). Segundo Freitas (2012), 425 milhões de pessoas no mundo utilizaram o Facebook em dispositivos móveis (Celulares, Tablets, etc.) em dezembro de 2011.

Segundo a Revista Info Online (2011), o relatório da comScore aponta crescimento de $20 \%$ da população brasileira no uso da Internet, passando de 33,3 milhões em 2009 para 40 milhões em 2010. O uso de redes sociais cresceu 10\%, tornando-se a segunda maior categoria de uso, atrás apenas de buscas, sendo que o crescimento do Facebook no Brasil foi de 258\% em 2010 atingindo quase 12 milhões de perfis a mais, contra $28 \%$ de crescimento do Orkut.

\begin{abstract}
Você se lembra da vida antes do fax, do e-mail e da busca online? Você se lembra de marcar uma consulta no seu médico para ter uma opinião sobre determinada doença sem dar uma olhada no Google antes? É como um filme que você assistiu anos atrás, cujo enredo lhe é vagamente familiar, mas sem nenhuma relevância na sua vida cotidiana. É assim que você vai pensar da web atual versus a web social que está se expandindo diariamente. O epicentro da social web é o Facebook. Você já sabe que o site tem mais de 500 milhões de usuários. Mas você sabia que as pessoas gastam 700 bilhões de minutos na gigantesca rede social por mês, ou que o Facebook acaba de ultrapassar o Google como o site número um da internet? O planeta é todo Google e Facebook atualmente e nós apenas surfamos em suas ondas (VALLS, 2010, p. 1).
\end{abstract}

"Depois do Twitter, a geolocalização" (BALDRATI, 2010, p.1). O mercado da Internet produziu em sua história inúmeras inovações em relação a novas formas de comunicação, comercialização e divertimento. Navegadores como o Mozilla Firefox, redes sociais como o Twitter e Facebook, sites de compartilhamento de imagens como o Flickr e Picasa, citando ainda programas específicos como Foursquare, Gowalla, Yelp, Booyaha, fazem parte de uma recente proposta que promete aquecer essa economia. A Geolocalização Social, com a interpolação remota ${ }^{3}$ dos dados de GPS de um smartphone com acesso a Internet, cria novos parâmetros para comunicar-se com sites online sobre sua posição geográfica atual, estabelecer relacionamento social com outros usuários, produzir e consumir formatos de produtos e serviços personalizados para as suas coordenadas (KARASINSKI, 2011).

\footnotetext{
${ }^{3}$ A geolocalização pode ser utilizada a partir de um endereço de IP (identificação de acesso do usuário do computador), MAC, RFID (identificação de radiofrequência), conexão sem fio e coordenadas de um GPS.
}

Cad. de Pesq. Interdisc. em Ci-s. Hum-s., Florianópolis, v.13, n.102, p.153-177 jan/jun 2012 
Neste cenário, traçamos alguns conceitos e características que acometem no cotidiano dos brasileiros que tem contato com as redes e mídias sociais.

\section{Hipermobilidade estética: ser notado na internet}

Se hoje se pode falar que na Internet existe, através de redes sociais e microblogings, uma "sociedade do espetáculo" como afirma Debord (1997), é porque nessa sociedade existe um consumo do espetáculo, muito mais do que se tem e do que se é, ao nível do que pelo menos "aparenta" ser ou ter, com um sujeito que busca se sentir importante através do (re)conhecimento e aparência que revela em sites, blogs e perfis sociais. A possibilidade que o ciberespaço oferece ao indivíduo, de se comunicar com um alcance que ignora limitações anteriores de tempo e espaço, fomenta uma relação mediada por imagens, textos e vídeos com um espetáculo que se apresenta em toda parte, fundando, segundo Baudrillard (1991), uma sociabilidade hiper-realista em que o real se confunde com o modelo, onde a humanidade não exige mais que os signos tenham algum contato verificável com o mundo que supostamente representam.

\footnotetext{
Já não existe o espelho do ser e das aparências, do real e do seu conceito. Já não existe coextensividade imaginária; é a miniaturização genética que é a dimensão da simulação. O real é produzido a partir de células miniaturizadas, de matrizes e de memórias, de modelos de comando - e pode ser reproduzido um número indefinido de vezes a partir daí. Já não se tem de ser racional, pois já não se compara com nenhuma instância, ideal ou negativa. É apenas operacional. Na verdade, já não é o real, pois já não está envolto em nenhum imaginário. É um hiper-real, produto de síntese irradiando modelos combinatórios num hiper-espaço sem atmosfera. Nesta passagem a um espaço cuja curvatura já não é a do real, nem a da verdade, a era da simulação inicia-se, pois, com uma liquidação de todos os referenciais (BAUDRILLARD, 1991, p. 8).
}

O desenvolvimento da técnica permitiu ao homem prolongar e projetar para fora de si uma potência que foi ainda ampliada no ciberespaço, onde o real pode ser potencializado pelo virtual. A semente é a virtualização da árvore, pois ali está o potencial para seu desenvolvimento (LÉVY, 1996).

Para Sibilia (2008), nesses novos arranjos de comunicação e sociabilidade, as pessoas legitimam suas formas de ser e estar no mundo através da exposição de intimidades e confissões na Internet. São identidades individuais e coletivas, 
experiências íntimas, pessoais e performáticas expostas de forma intencional, negociada, espetacularizada e reivindicadas como autênticas. Não se trata mais da discussão do real ou do virtual, mas da participação dos internautas em um espaço híbrido no qual o "extremamente privado" e o "absolutamente público" se fundem constantemente.

A "fabricação" de subjetividade alcançada nas redes sociais vai além da espetacularização do "eu", ali se constrói um eu personalizado, estilizado, imagem e parte de si, para além de um espelho de si visível nas telas. Para Sibilia (2010a):

[...] mudaram as premissas a partir das quais edificamos o eu, [...] se quisermos "ser alguém", temos que exibir permanentemente aquilo que supostamente somos. [...] Esses são os valores que têm se desenvolvido intensamente nos últimos tempos, uma época na qual, por diversos motivos, se enfraqueceram as nossas crenças em tudo aquilo que não se vê, em tudo aquilo que permanece oculto (p.1).

Ao ficar visível, faz-se do próprio "eu" um show e nem a intimidade tem o mesmo sentido que tinha. Converte o mundo em um cenário onde todos devem se mostrar e, através das redes sociais, mudam na mesma velocidade da Internet em novas formas de se relacionar com os outros. Para completar esse sentimento de existência, Sibilia (2010) afirma que esse fenômeno perpassa por um anseio de se mostrar, estar presente virtualmente na observação dos outros. Muda-se o sentido, não precisa mais aparecer para os outros crerem que ele exista, projeta-se enquanto identidade nas redes sociais para reforçar a segurança de existência de si mesmos, como meta auto justificável.

[...] o que pedimos aos outros é, em primeiro lugar, que reconheçam nossa existência (é o reconhecimento ao pé da letra) e, em segundo lugar, que confirmem nosso valor (denominemos essa parte do processo de confirmação) [...] Reciprocamente, a admiração dos outros é apenas a forma mais visível de seu reconhecimento, pois se refere a nosso valor; mas seu ódio ou agressão também o são, embora de maneira menos evidente: atestam com a mesma intensidade nossa existência (TODOROV, 1996, p. 94).

A necessidade de um "espelho virtual" a qual adorna sua beleza, influência e potência através de fotos com uso de Photoshop, perfis com mais de mil pessoas adicionadas, e pessoas respondendo aos comentários mostrados na rede, se 
tornaram os meios mais eficazes de transmissão de notícias e democratização do acesso à fama.

A pergunta que fica é sobre o que ainda é íntimo e privativo nas redes sociais, já que o que escondemos de alguns é visível para os sistemas de marketing de empresas como a do Google e do Facebook. Sibilia (2010) declara que os caminhos que seguimos até aqui não devem ser apenas anúncios do medo de nos expormos sem limites pela Internet, pois da forma como construímos nosso "eu" hoje, se deixarmo-nos ocultos na intimidade, correríamos o risco de um sentimento de não existência.

Numa sociedade tão espetacularizada como a nossa, a imagem que projeta o "eu" é o capital mais valioso que cada sujeito possui. Mas é preciso ter a habilidade necessária para administrar esse tesouro, como se fosse uma marca capaz de se destacar no competitivo mercado atual das aparências.

Além disso, para Sibilia (2010) “[...] sempre será possível mudar de 'perfil', atualizando as informações pessoais ou alterando suas definições para melhorar a cotação do que se é" (p.1).

\section{Dispositivos de controle de circulação: ser encontrado na Internet}

Ser notado virou um dos objetivos principais do sucesso da WEB 2.0, porém, segundo Sibilia (2010), o Facebook e Orkut são sistemas que incentivam pelo desejo de estar conectado, a necessidade de acompanhá-los por maior tempo possível, muitas vezes um acompanhamento online de uma solidão real.

\footnotetext{
Utilizando as mais diversas ferramentas tecnológicas (celulares, e-mail, GPS etc.), aprendemos a estar sempre disponíveis e potencialmente em contato. Acredito que tudo isso esteja dando conta de um forte desejo de estar à vista dos outros, de sermos observados, mesmo que seja apenas para confirmar que estamos vivos. Para constatarmos que somos "alguém", que existimos. Sem dúvida, entre várias outras coisas, há muita solidão e vazio por trás de tudo isto (SIBILIA, 2010, p.1).
}

Ao tratar das tecnologias de localização remota, controle de fluxos e circulação de pessoas, condutas e serviços, há a necessidade de rever a ferramenta de marketing construída a partir do sistema já explicado neste projeto, chamado geoprocessamento. O geoprocessamento pode ser explicado de forma simples se 
disser que é a união dos conhecidos mapas do Google Earth com informações estatísticas populacionais, de serviços e políticas públicas. Agregando informações espaciais cartográficas e dados atualizados por cadastros imobiliários e pesquisas com cidadãos, um software processa esses dados de forma gerencial fazendo um verdadeiro "raio-x" geo-estatístico de uma cidade ou empresa, determinando a situação "orgânica" de uma população e possibilitando a melhoria da gestão organizacional pública ou privada. Uma dessas utilidades é o Geomarketing ou Marketing Geográfico. Com ele permite-se visualizar o mercado na forma que ele se organiza no espaço, ou seja, permite a análise das variáveis relevantes para o Marketing através da visualização de dados em mapas geográficos. Uma empresa, antes de abrir, agora pode ter muito mais subsídios sobre a população alvo que circula no raio que parte de sua empresa (serviço oferecido pelo Serviço de Apoio às Micro e Pequenas Empresas - SEBRAE, no Brasil), objetivando em um plano de comunicação e marketing muito mais eficiente, pois se conhece o perfil daquela comunidade, sua circulação e motivações, seus hábitos diários e principalmente informações de seu consumo.

Essas contribuições, que a rede de informações formada pelas empresas que fazem serviços de geomarketing constrói, acaba sendo muito útil, mas ficando obsoleta caso a coleta não tiver atualização constante. Diferente disso, o controle estabelecido por softwares e redes sociais consegue essas informações de uma forma muito mais rápida e com mais detalhes íntimos, porém com a mesma lógica de controle. No caso das redes sociais a intimidade é revelada em informações pessoais e confidenciais para subsidiar propagandas, mecanismo de realidade aumentada e estratégias do Facebook, através de fotos, contatos com outras pessoas, preferências e hábitos. A partir do número de um IP ou da revolução da comunicação móvel através dos celulares com GPS embutidos, os acessos a essas redes sociais são os novos motivos de comemoração das grandes empresas "ponto com".

A questão é a gestão qualificada dos clientes e da distribuição de publicidade com "disparos" de propaganda bem mais eficientes. No caso das mídias sociais, as empresas compram cliques em anúncios totalmente direcionados a perfis dentro de redes sociais, comprando inclusive palavras-chave em buscadores como o Google, que filtram seus alvos de atuação. Se no geomarketing pode-se determinar a localização dos utilizadores na escala do país, cidade, rua, ou a partir do ponto da 
empresa (por exemplo, todos os clientes num raio de $5 \mathrm{~km}$ a partir delas), podendo fazer buscas pelas tendências de consumo e hábitos dos consumidores, no caso das redes sociais, quando se possui um celular, considerado um objeto hiperpessoal, os anúncios não ficam mais expostos em um outdoor onde irá circular por ele de carro uma vez ao dia; a notícia, atualização, mensagem ou feed vai diretamente a esse objeto íntimo que se carrega junto ao corpo o dia inteiro e, inclusive, perto de você, quando for dormir.

O marketing é agora o instrumento de controle social, e forma a raça imprudente dos nossos senhores. O controle é de curto prazo e de rotação rápida, mas também contínuo e ilimitado, ao passo que a disciplina era de longa duração, infinita e descontínua (DELEUZE, 1992, p.223).

Quando se consegue isolar as estratégias dessas relações de força que suportam tipos de saberes e vice-versa, podemos conceber, então, um dispositivo. Seja em Foucault (1987), na descrição feita do Panóptico de Bentham e das sociedades disciplinares como arquitetura de governo, ou em Deleuze (1992) pautando as sociedades de controle, o que está em jogo são formas de se exercer o poder, apoiadas em instrumentos de saber, produzindo efeitos de subjetivação e sujeição. O geoprocessamento mesmo com informações fidedignas de dados populacionais, serviços públicos, censos, cadastros imobiliários, e um conjunto de imagens e de informações de localização dos corpos que se movem naqueles espaços podem ser considerados apenas o primeiro passo para as novas estratégias de marketing nas mídias sociais. O foco agora é um tipo de dispositivo de controle de circulação emergente na última década, que remete ao rastreamento das atualizações de usuários nas redes sociais.

Agamben (2005) afirma que "[...] dir-se-ia que hoje não haveria um só instante na vida dos indivíduos que não seja modelado, contaminado ou controlado por algum dispositivo" (p. 13). Além de tornar visíveis os produtos e serviços ofertados, agora sua localização, conjunto de informações e cliques na Internet fazem com que um sistema inteligente, com uma programação robótica, recomende livros, filmes, músicas e, inclusive, aponte supostas pessoas que podem ser seus amigos ou conhecidos. Os "Sistemas de Recomendação", aqui revelados em pesquisas dentro da revisão de literatura, analisam as avaliações conhecidas e preveem qual será a pontuação de um usuário para um item ainda não avaliado. Por 
uma seleção colaborativa, unindo experiências coletivas de outros usuários parecidos com seu perfil, por fatores latentes que usam seu histórico de escolhas dentro de determinada página de produtos, com palavras-chave digitadas em sistemas de buscas, e milhares de algoritmos e matrizes de similaridades entre itens e pessoas, os filtros tentam predizer por similaridade os próximos passos dos seus usuários, calculando seus desejos e intenções (LÁZARO, 2010).

Desde empresas como o Facebook e Twitter, grandes redes de locadoras de filmes, como a NetFlix, rádios pela Internet, como a Lastfm, comunidades de compartilhamento de vídeos, como o Youtube e Dailymotion, sistemas próprios de geolocalização social, como Foursquare, Gowalla e Facebook Places, têm seus sistemas próprios de recomendação de produtos e serviços. Na perspectiva de Lévy (1996) o virtual significa algo que existe em potência e se opõe ao atual, e a realidade virtual é a geração de um mundo a partir de uma relação homem-máquina, criada artificialmente e onde o usuário pode 'habitar'. Se falarmos sobre a velocidade que as informações entram em contato com a realidade de quem apreende, da significação de cada um, através dos novos formatos de sociabilidade dos sujeitos com a Internet, o atual em potência é muito eficiente, as propagandas personalizadas e lançadas diretamente ao público parecem ser ainda mais efetivas que o Geomarketing realizado com o geoprocessamento. Com público diferente, o mapeamento e avaliação de pontos de venda: localização, visibilidade, acessibilidade, produtos, preços, perfil dos clientes permitem outros tipos de negócios além dos dispostos na Internet. Mas a latência do virtual forma nesse caso um dispositivo tão atual, instantâneo e global, com discurso que emerge produções de verdades similares a sua identidade virtual-real, formando uma rede de controle com conhecimento técnico matemático que sincroniza sua subjetividade as pretensões das grandes corporações da Internet.

Com o contato que o celular assumiu com o nosso corpo, muito além de um sistema móvel de comunicação falada, existem novos desafios para as fronteiras que expõem além de intimidades, códigos de localização via GPS integrado e um canal de propagação de publicidade. Nessa condição, o Geomarketing e os sistemas de marketing por Geolocalização Social necessitam de questionamentos. Para quem será comercializada suas informações, o mapa de suas circulações, e que tipo de governo eletrônico pode ser gerado com elas? Como o "Mobile Marketing" vai ajudar a construir subjetividades e condutas a partir de informações 
direcionadas e tensionadas a sua localização, necessidade e perfil? Serviços que informam a localização do usuário têm o potencial de alterar a relação entre empresas e consumidores?

Valls (2010) aponta previsões de estudiosos em marketing sobre o Facebook Places, o primeiro passo do Facebook para oferecer serviços de geolocalização. Desde seu início, os prognósticos caminham para criação de estratégicas comerciais em descontos para grandes grupos, em promoções para conjuntos de usuários, como, o aparecimento de "comportamento de enxame" no consumo de determinadas empresas e produtos, ou na expectativa das informações alcançarem o mesmo status viral que já causam notícias polêmicas ou vídeos curiosos no Youtube. Outro fator será a competição acirrada entre as empresas sabendo do mercado promissor e do que já significa o lucro das compras pela Internet e da eficiência da sua publicidade, gerando uma nova dimensão aos programas de gestão de relacionamento com clientes. Sabendo disso, problemas como o da privacidade da localização do consumidor ainda são dilemas relevantes e contínuos que revitalizam os dispositivos de vigilância, porém, ao mesmo tempo, são esses mesmos dispositivos que abrem portas para um novo tipo de subjetividade que busca na visibilidade uma oportunidade para também se fazer "eu" no mundo que o cerca.

\section{Fetiche e consumo de inovação ${ }^{4}$ : estar atualizado}

No cenário da mobilidade, das redes sociais, dos dispositivos de geolocalização e do amplo acesso à Internet pela população, a técnica é mantida em seu disfarce, a mercadoria naturalizada, o sujeito objeto de trocas comerciais, muito mais em foco aqui, o próprio estatuto do uso das tecnologias. Para Garcia dos Santos (2005), a discussão do Estatuto da Tecnologia quase não existe no Brasil, obstante aqui se conseguir discutir políticas tecnológicas.

Aqui, o problema da tecnologia soma-se ao fato de que o país é pobre. Em país pobre, tecnologia é fetiche. Em que sentido é fetiche? Se você pode aceder à tecnologia, isso faz uma diferença, e é uma diferença de status, de prestígio. A tecnologia faz uma diferença social. Então, o entendimento de que se está dentro do progresso ou da evolução tecnológica é feito pela via do consumo, e não pela via da produção ou da inovação. As elites pensam

\footnotetext{
${ }^{4}$ Lembrando que inovação é o melhoramento de algo que já existe, algo novo, chama-se invenção.
} 
que basta aceder ao uso para se alcançar a modernidade. É por isso que considero a discussão muito limitada: o máximo que se consegue é o acesso a ela através do uso, e não a sua produção. Acho que precisamos, no Brasil, de um estudo aprofundado sobre a questão da tecnologia como fetiche, de como ela é apropriada como uso suntuário e ostentação (p.1).

Esses dispositivos de localização nas redes sociais tem o efeito do "consumo" como combustível e remete a questionar sobre que status, que tipo de antropologia do desejo, fetiche ou busca por aceitação social que retroalimenta esse sistema de compras de acesso, de relato e trocas de informações íntimas e de produção de relacionamento e risco, por circular "nu" pelos interstícios da Web. Um sistema aparentemente caótico inclina o comportamento de sujeitos em larga escala nas redes sociais, com identidades que se propagam e se "fetichizam", virando elas mesmas os bens de consumo.

O novo adestramento do indivíduo efetua-se, pois, em nome de um "real" que é melhor acatar com resignação do que se opor: ele deve parecer sempre agradável, querido, desejado como se se tratasse de entertainments (televisão, publicidade...). Ainda não se analisou bem a incrível violência que se dissimula atrás dessas novas fachadas soft [...] (DUFOUR, 2005, p.1).

Para Dufour (2005), o pleno desenvolvimento da razão instrumental (a técnica), junto ao enredo capitalista, pós-moderno e neoliberal, resultou num déficit da razão pura, da condição de julgar o que é verdadeiro ou falso, derivando no que ele chama de redução das mentes. O indivíduo, em seu sentido mais banal, teve que se adaptar a técnica e aos fluxos sempre instáveis da circulação da mercadoria, num sistema de trocas que o levou a uma verdadeira mutação antropológica, uma transformação na condição humana.

Oakeshott (1999) explica que se tivesse que pegar pelo menos cinco dos últimos anos, qualquer

[...] desconhecido sem preconceitos poderia plausivelmente supor que amamos a mudança, temos apenas o apetite pela inovação e que nos falta ou autoestima ou cuidado com nossa identidade, já que não parecemos dispostos a dispensar-Ihe qualquer consideração (p. 25).

Ele descreve que o que sentimos é um fascínio pelo que é novo, mais profundamente do que o conforto com o que é familiar, em um nível que já achamos pouco o preço a ser pago pelo risco da inovação. Existe algo incontido no ser 
humano que se habituou à mudança, com a expectativa de grandes inovações em perspectiva, e com a sensação de que tudo é produto perecível, sendo que o que se compra já prepara para ser consumido, deteriorado e substituído.

Há um preconceito positivo em favor daquilo que ainda não foi
experimentado. Presumimos facilmente que toda mudança é, de alguma
forma, para melhor, e persuadimos facilmente de que todas as
consequências de nossa atividade inovadora são ou melhoramentos por si
mesmas [...] (OAKESHOTT, 1999, p. 25,26).

A descrição dos dispositivos de controle de circulação e propagação de propagandas direcionadas na Internet faz parte do mesmo mercado ou capital, que só sobrevive com a inovação tecnológica incessante. Estamos falando de práticas sutis de se exercer poder, com forte suporte científico, que permitem adaptabilidade, sutileza, mobilidade e plasticidade, precisamente os traços que definem 0 funcionamento do poder (FOUCAULT, 1979). Novas dúvidas aparecem. Como se cria um feitiço de sedução para a técnica garantir seu espaço e não gerar resistência? A sedução do progresso e das novas tecnologias de geolocalização e redes sociais são um fetichismo do capital, um impressionismo de métodos publicitários, ou é um fenômeno das máquinas antropológicas, inerente à volição e subjetividade?

Zizek (2008) comenta que o fetichismo da inovação existe num mercado que se reproduz na lógica de produzir tecnologia, lucro e mais valia, porém desde Lukács, Jameson e Adorno, existiu uma fissura ou armadilha do fetichismo da mercadoria. Ao atribuir que a consciência dos trabalhadores estava ofuscada por certas leis da sedução da sociedade de consumo, mecanismos ideológicos, libidinais (citando a psicanálise) que mantêm os trabalhadores sob o feitiço da ideologia burguesa, não se deram conta da insuperável lacuna paraláctica que o produto tem de dar para afirmar-se como mercadoria e que o capital industrial também obtém mais valia a partir das fissuras entre dois sistemas diferentes.

Contrapondo a isso, Arendt (1988) discorda que a revolução das técnicas modernas seja resultado de uma evolução natural e, psicologicamente falando, diz que não estaremos mais preparados para evidenciar uma condição que vai ser um novo drama no desenrolar da História. O momento que tornará os "[...] homens 'conservadores' e não 'revolucionários', ávidos em preservar o que foi realizado e assegurar sua estabilidade, ao invés de se mostrarem receptivos às coisas novas, 
aos novos avanços e novas ideias" (p.33). Mesmo a inovação tecnológica podendo ter vida própria no desejo de muitos consumidores, e essa, uma característica marcante do mundo em que vivemos, ela não deve ser confundida sob uma plataforma de revolução de nossa época, pois inovação a qualquer preço deve ser cuidadosamente diferenciada de uma nova fase, mas de um desafio confuso presente, indeciso a resistência, desejo ou subversão.

\section{A negação do progresso: ser recomendado}

A ideia de inovação na era dos sistemas de recomendação veio a partir do conceito de "crowdsourcing". Trata-se de um método de criação que conta com a participação de milhares de pessoas em torno de um objetivo. A teoria prega que diferentes pessoas têm diferentes perspectivas sobre um mesmo tema, ajudando a inovar melhor, mais rápido e mais barato.Muitas empresas já aplicam isso ao seu negócio. "A companhia de locação de filmes online Netflix está reeditando uma experiência bem-sucedida: um concurso em que premia com US\$1 milhão quem criar um sistema de recomendação mais eficiente" (BARIFOUSE, 2009, p.1).

O anúncio era para que descobrissem métodos de recomendação que superassem a eficiência dos métodos existentes em 10\%. Essa qualidade na recomendação tem um motivo muito impactante nas vendas. Segundo Anderson (2007), estamos saindo da era da Informação e entrando na era da Recomendação, o formato de vendas pela Internet impulsiona um volume de negociações que não se explicam mais pelas leis de mercado conhecidas. A Amazon revela que entre $25 \%$ e $33 \%$ de suas vendas vem de recomendações de seu sistema, o Youtube afirma que $30 \%$ dos vídeos assistidos são de sugestões feitas por computador, sendo que o sistema da Netflix seria capaz de acertar com $75 \%$ de precisão qual nota você daria para um filme visto em sua rede, ou se gostaria dele ou não, antes de você mesmo assisti-lo. Segundo Kahney (2008), no livro “A cabeça de Steve Jobs”, Jobs havia argumentado que "[...] as pessoas não sabem o que querem até você mostrar a elas. Como disse certa vez Henry Ford: 'Se eu perguntasse a meus compradores o que eles queriam, teriam respondido que era um cavalo mais rápido"” (p. 28). Nos sistemas de buscas existe a compra de palavras-chave relativas a uma marca desejada, um sistema de recomendação de palavras e produtos, e uma corrida atual 
para defender essas marcas de problemas e reclamações nos resultados das buscas e dentro das redes sociais.

A Comissão Gulbenkian (1996) relatou sobre a enorme ênfase dada ao conceito de sobrevivência do mais "apto", na justificativa de quem tem o domínio maior e mais rápido da técnica, esteja se defendendo de alguma forma contra a extinção. "Assistiu-se, assim, à utilização de interpretações demasiado livres da teoria da evolução para dar legitimidade científica ao pressuposto de que o progresso culminava nessa auto evidência que era a superioridade" (p.48, 49).

\footnotetext{
Durante muito tempo se pensou que as ciências, o saber, seguiam uma certa linha de "progresso" obedecendo ao princípio do "crescimento" e ao da convergência de todas essas espécies de conhecimento. No entanto, quando se vê como se desenvolveu a compreensão europeia, que acabou por se tornar a compreensão mundial e universal, histórica e geograficamente, será que se pode afirmar que houve crescimento? Eu diria que se trata antes de transformação (FOUCAULT, 2006, p.104).
}

A sobrevivência das companhias está acontecendo por vias muito mais adaptativas a concorrência do que em função de desenvolvimento tecnológico responsável para a humanidade. Cria-se qualquer coisa melhor que o concorrente sem problematizar legitimidade, coerência, ou mesmo os impactos e riscos para população. Deixa-se de lado o Ethos científico baseado na transparência e bem comum, o desinteresse financeiro é repudiado como ingenuidade e as redes sociais transformadas em redes comerciais.

Por isso problematiza-se a conjuntura do desejo humano por inovação como processo naturalizado em um comportamento que acaba vinculando a ideia de "progresso" a de crescimento, evolução e desenvolvimento sempre com caráter positivo. Brüseke (1998) diz que a técnica parece possuir uma autopoeisis, um fator de continuidade autônomo que derruba paulatinamente o que a faz afastar da imagem do progresso e da sua respectiva identidade.

Scheibe (2010), no contexto do ecodesenvolvimento, explica esse ponto chave através de perguntas a era de desafios populacionais com a natureza. Será que não estamos exercendo uma fé autorizada no progresso da humanidade? 0 (des)envolvimento, desembrulhar das inovações tecnológicas não estão travestidas em "pele-de-cordeiro"? Como compreender historicamente a ligação das palavras desenvolvimento e inovação como criadora de benefícios? Scheibe (2010) chama atenção que, pelo menos na área da economia da natureza, temos que pensar que 
talvez não precisemos de desenvolvimento, de mudança, mas sim lutar para permanecer como está. Porque as grandes mudanças estão indo na sua maioria rumo aos interesses do capital. Ser conservador não é mais se posicionar ao medo dos riscos, mas marcar posição frente ao desenvolvimento, o discurso da evolução e da inovação, que se encontra hoje com muito mais possibilidades de piorar a situação da vida humana na terra.

\section{Risco viral do uso da técnica}

Focar nos riscos e provocar temor ao futuro, quando o assunto é a inovação através técnica, parece contraditório ao desejo de tantas pessoas, a segurança propagada pelos cientistas na mídia, as propagandas de grandes corporações, no conjunto de interesses econômicos, na "inoculação" de novos produtos no seio do consumo. Brüseke (1998) relata que esses posicionamentos não aparecem num conjunto tão diverso de autores como Heidegger, Beck e Marcuse ou Horkheimer e Gehlen, que, referente à questão da técnica, compactuam com uma preocupação em comum: o tom de alarde ao deslocamento cada vez mais independente da técnica dentro da sociedade humana, no seu ambiente natural e através do desempenho das ciências da informação.

Os investimentos gigantescos no desenvolvimento de "novas tecnologias", seja pelo Estado ou pela própria indústria, contrasta com o mal-estar que os críticos da técnica expressam. Aparentemente continuam, tanto os países industrializados quanto as regiões que abrigam a maioria da população da sociedade global, com uma política que favorece a introdução acrítica de qualquer inovação técnica ao alcance dos governos e do empresariado local (BRÜSEKE, 1998, p. 10).

Para Oakeshott (1999), estamos refeitos de piedades transitórias, lealdades evanescentes, escondidos no ritmo da mudança que nos previne contra ligações demasiadamente profundas. Estamos falando da condição humana em um milênio que abriu já com expectativas relevantes com intermédio da tecnociência. Prazo de 15 anos para vacina da AIDS, 8 milhões de anos para explosão do sol, 10 anos para chegar em Marte, 20 anos para a cura do câncer. Todos dispostos a tentar qualquer coisa uma vez e, se esquecendo das consequências, cada atividade e ser humano competindo um com outro para ser considerado "atualizado", primeiro, melhor, mais rápido, mais virtual. 


\begin{abstract}
Ver é imaginar o que se poder ser, em lugar do que é; tocar é transformar. Qualquer que seja a forma e a qualidade do mundo, ele não permanece por muito tempo como o desejamos. E os que se dedicam ao movimento contagiam os demais com sua energia e empreendimento. Omnes eodem cogemur, quando não mais somos ágeis, encontramos um lugar para nós no movimento geral ("Quem dentre nós", pergunta um contemporâneo, não sem certo equívoco, "não preferiria, qualquer que fosse o custo em ansiedade nervosa, uma sociedade febril e criadora em lugar de uma sociedade estática"?) (OAKESHOTT, 1999, p. 25).
\end{abstract}

O debate sobre a técnica nos anos 90 tomou o rumo das discussões em seu aspecto tecnocrático. Desde a imaginação de um mundo técnico e politicamente totalitário, de publicações e eventos científicos preocupados com a questão das instabilidades e riscos provocados pela introdução de novas técnicas, até políticos, organizações não governamentais e empresas preocupadas com seu visual no mercado, buscando alternativas ambientais e investimentos em marketing e campanhas ecológicas (BRÜSEKE, 1998).

Como avaliar os riscos, as formas obsessivas de como alguns transformam a Internet em seu espaço e meio de sobrevivência, o uso indevido, a exposição arriscada de informações e dados pessoais? Riscos, diz Beck (1993), "[...] são formas sistemáticas de lidar com os perigos e as inseguranças induzidas e introduzidas pelo próprio processo de modernização" (p. 21). Risco não é uma invenção moderna. O risco que sempre existiu, porém, era tanto mais pessoal, quanto mais visível e sensorial. Agora as reações colaterais da manipulação genética, dos excessos de produção industrial, e das fórmulas físico-químicas são ao mesmo tempo retidas ao laboratório, produzidas em larga escala e vendidas envoltas por belas embalagens que seduzem consumidores.

De acordo com Beck (2007), nas últimas décadas, o que mudou foi a natureza do risco, pois na primeira modernidade há uma confiança no progresso e no controle do desenvolvimento científico-tecnológico, e na previsão de uma segunda modernidade o desenvolvimento técnico-científico não daria mais conta de controlar e prever os resultados que os riscos ajudaram a criar. Esses seriam riscos de alta consequência, e pelo seu caráter de irreversibilidade, como, por exemplo, riscos ecológicos, virais e nucleares seriam "democráticos": afetariam a todos, ultrapassando fronteiras de países e classes sociais. E o mais curioso. Existiriam tentativas repetitivas para encontrar soluções nesse nível, e a produção científica 
que fez ocasionar a crise será ainda mais usada para tentar resolver e reverter esse processo. Contra a ciência, mais ciência.

Essa noção não se compreende por alarmismo, ativismo ou ideologias políticas, mas a clara discussão para quem analisa fenômenos sociais em pesquisas sobre novas tecnologias: "Na modernidade tardia, a produção social de riqueza é acompanhada sistematicamente pela produção social de riscos" (BECK, 2007, p.19).

Segundo Beck (2007), as informações são direcionadas e os discursos de risco são delegados para serem decididos pelos próprios cientistas que os criam, todos financiados por grandes corporações, que tem o objetivo de jogar a verdade do risco para junto de zonas de fronteira, aprovadas mais adiante por pressão política ou por nada provarem contra. Decidido ou convencionado pelos sistemas peritos, os riscos dos transgênicos ou das torres de celular, por exemplo, são democratizados pela tecnologia e se espalham sem muitas ressalvas. Beck (1993) diz que a ciência está se tornando humana, pois passou a ser sujeita a erros e essa noção de conectividade, compartilhada com Guiddens (1991), indica não a capacidade de mortalidade do risco, mas sim sua viralidade, que pode se espalhar em poucas horas para o mundo todo. Informações sigilosas expostas por um site chamado Wikileaks (Ciência Política), a notícia da crise imobiliária nos EUA (Ciência Econômica) ou o vírus influenza A H1N1 (Ciência Biológica) mostram que as ciências cometeram alguns erros sobre impacto mundial de sua influência, principalmente quanto à viralidade.

São riscos que extrapolam também as fronteiras temporais: não apenas nós, mas as gerações futuras estão "em risco". Olhamos para as catástrofes do passado e as esquecemos. O sentido de futuro, de que a ameaça e risco virá daqui a 10 ou 50 anos, gera uma percepção sempre procrastinada de um risco que está sempre longe de acontecer. A significação temporal se baliza na questão espacial, em relação à distância do risco. Se ele não se encontra "no seu quintal", onde também é visível, poucos se manifestam. Douglas \& Wildavsky (1982) explicam que essa noção é democrática e cultural, e o que a maioria das pessoas pensa é: que o risco recomendado é uma ficção científica. 


\section{Considerações finais: rede social, risco social?}

"O Facebook não vende suas informações para anunciantes" (FACEBOOK, 2011, p.1). Esta é uma das frases presentes dentro das configurações de privacidade da rede social mais acessada do mundo. Por outro lado, nesse mesmo site, é oferecido ao público propostas para a compra de anúncios intimamente direcionados para os perfis pessoais dos usuários.

Quem tem um perfil dentro da rede do Facebook não têm suas informações vendidas, mas elas têm uso comercial para quem quer anunciar dentro da sua página, no lado direito da formatação, usando dados do seu perfil e das coisas que você "curte" ou tem interesse. Quanto mais campos preenchidos, melhor será a precisão de um anúncio. As informações vão desde o alcance específico de sua cidade, ou de 16 a 80 quilômetros a partir dela, perfil demográfico de 13 a 64 anos, gênero masculino ou feminino, palavras que as pessoas curtem (palavras-chave que se encontram nos perfis alvos), e também detalhes avançados, como datas de nascimento, perfis de relacionamento (solteiro, relacionamento sério, noivo, ou casado), nível de formação acadêmica, empresa que trabalha ou rede de negócios que faz parte, sempre readaptando automaticamente o envio de acordo com a atualização dos perfis que mudam com o tempo. Dessa maneira, o contratante paga valores por clique, com preços diferenciados e possibilidade de cotas de dólares gastas por dia (semelhante ao Google e seus Links Patrocinados), programando o tempo que a campanha vai ficar presente. Após preencher os dados sobre o público alvo do contratante, o Facebook mostra uma estimativa de quantas pessoas irá atingir com aquela proposta, um alcance estimado para quantos perfis parecidos, ou exatos com o que escolheu nas configurações, vai aparecer esta propaganda.

Apesar do próprio dono do perfil personalizar suas configurações de privacidade e segurança, elas vão ser manipuladas pelo sistema e correm o risco de exposição para pessoas mal intencionadas. Talvez a evidência dos riscos ultrapasse o medo de exposição ao crime, aos fakes (perfis com identidades falsas), ou o uso excessivo pelos adolescentes, que tem seu desempenho escolar prejudicado. Apesar das redes sociais serem defendidas como ótimo espaço para melhorar o networking, ou como instrumento de trabalho e espaço de publicidade para empresas, tem sido difícil para as empresas controlarem seu bom uso. Além de tirar muito tempo de profissionais, elas foram motivo de problemas com demissões, 
informações divulgadas equivocadamente e em muitos casos, os dados influenciaram nos processos seletivos de contratação.

O que chama atenção é que mesmo havendo esses riscos de segurança da informação, de imagem e de privacidade on-line, a adesão às redes aumenta vertiginosamente. O temor da chamada "invasão de privacidade", segundo Sibilia (2010), dá espaço para o quase oposto: o aparecer, ser visto, contemplado e admirado. Nem mesmo a possibilidade de ser rastreado pelo celular com GPS, ter sua vida vasculhada na rede, ter identidades roubadas com o furto de senhas, ou mesmo, o risco do isolamento social, tendo mais amigos virtuais que reais, são motivos para diminuir os acessos. Segundo Oakeshott (1999), estamos dispostos

[...] a jogar em nossas fantasias individuais com poucos cálculos e nenhuma apreensão pela possível perda. Somos aquisitivos ao ponto da cobiça; prontos a largar o osso que temos na boca em troca de seu reflexo aumentando no espelho do futuro (p.25).

Sibilia (2010) explica que é possível escolher divulgar ou não certas informações, porém deixar de participar delas tem sido um fator que cada vez mais limita o trânsito em diversos espaços sociais. "A superexposição nas redes sociais online tem seus reflexos na vida offline, assim como a simples ausência" (p.1). Os riscos que o uso da técnica nos oferece, pelas instituições que produzem discursos de facilidades, promoções de ferramentas e incentivo de condutas na Internet, manifestam que cada vez mais somos aquilo que produzimos na Internet, tanto enquanto sujeito, como em coletividade.

Quem define a tecnologia que está "determinando os impactos"? Quem a
controla? Os "impactos" são necessariamente os mesmos em todas as
sociedades? Se não, por quê? [...] Considero que entender o significado da
técnica é uma tarefa essencialmente política, na medida em que uma
clareza sobre a questão é fundamental tanto na tomada de decisões a
respeito do seu desenvolvimento, como no planejamento da sua adoção e
uso, seja por indivíduos, unidades familiares ou organizações.
Responsabilizar a técnica pelos seus "impactos sociais negativos", ou
mesmo seus "impactos sociais positivos", é desconhecer, antes de mais
nada, o quanto - objetiva e subjetivamente - ela é construída por atores
sociais, ou seja, no contexto da própria sociedade (BENAKOUCHE, 2005, p.
80).

Queremos sem riscos desejar e consumir mais. A crescente reflexibilidade da comunidade mundial entende que o controle racional não é suficiente para esses sentimentos humanos, o que levou a criação de acordos multilaterais para a 
regulação da pesquisa e da utilização de determinadas tecnologias, e consequentemente a normatização do risco. O maior problema é regular o desejo pela inovação, é barrar a vontade de existir esteticamente dentro das redes sociais e se localizar no mundo, apenas quando se consegue localizar seu ponto, seu espaço dentro da realidade virtual. 


\section{REFERÊNCIAS}

AGAMBEN, G. O que é um dispositivo? In: Outra travessia. (5a ed.). Florianópolis, SC: [s.n.]. 2005.

ANATEL - AGÊNCIA BRASIL. Em janeiro, telefonia móvel alcança 245,2 milhões de linhas ativas. 2012. Disponível em: <http://www.ae.com.br/institucional>. Acesso em: 15 fev. 2012.

ANATEL - AGÊNCIA BRASIL. Brasil já tem mais de $\mathbf{2 1 0}$ milhões de linhas de celulares. 2011. Disponível em: <http://www.ae.com.br/institucional>. Acesso em: 24 abr. 2011.

ANDERSON, C. A cauda longa. São Paulo: Actual Editora, 2007.

ARENDT, H. Da Revolução. O significado de revolução. São Paulo: Ática, 1988.

BALDRATI. B. Depois do Twitter, a geolocalização. Caderno de Tecnologia. 2010. Disponível em:

<http://www.gazetadopovo.com.br/posgraduacao/conteudo. $p h t m l$ ?tl=1\&id=985824\&ti t=Depois-do-Twitter-a-geolocalizacao>. Acessado em: 24 mar. 2010.

BARIFOUSE, R. Netflix oferece US\$ 1 milhão para quem criar sistema de recomendação mais eficiente. Revista Época Negócios, 2009. Disponível em: <http://www.m.colunas.época negocios.globo.com/netflix-oferece-us1-milhao-paraquem-criar-sistema-de-recomenda cao-mais-eficiente/>. Acessado em: 21 set. 2009.

BAUDRILLARD, J. Simulacros e simulações. Lisboa: Relógio d' Água, 1991.

BECK, U. Vivir em la sociedade del riesgo mundial. Living in the World Risk Society. Barcelona: Fundación CIDOB, 2007.

BECK, U. Sociedade del riesgo. Hacia una nueva modernidade. Barcelona:

Ediciones Paidós Ibérica, 1993.

BENAKOUCHE, T. Tecnologia é sociedade: contra a noção de impacto tecnológico. In: DIAS, L.C.; Silveira, R. L. L. (orgs.) Redes, Sociedades e Territórios. Santa Cruz do Sul: EDUNISC, 2005. 
BRÜSEKE, F. J. A crítica da técnica moderna. Estudos Sociedade e Agricultura, n. 10: 5-5, abril 1998.

COMISSÃO GULBENKIAN. Para abrir as Ciências Sociais. Para Reestruturação das Ciências Sociais. Immanuel Wallerstein. São Paulo: Cortez, 1996.

DEBORD, G. A Sociedade do espetáculo: comentários sobre a sociedade do espetáculo. Rio de Janeiro: Contraponto, 1997.

DELEUZE, G. Post-Scriptum sobre as sociedades de controle. In: DELEUZE, G. Conversações: 1972-1990. São Paulo: Editora 34, 1992.

DOUGLAS, M., Wildavsky, A. Risk and culture. An essay on the selection of technical and environmental dangers. Berkeley, CA: University of California Press, 1982.

DUFOUR, D. R. A arte de reduzir as mentes. Trad. Iraci D. Poleti. Paris: Denoël, 2005.

EXTRA. O Uso do celular no Brasil. 2011. Disponível em:

<http://imagens.extra.com.br/html/infografico/celular-no-brasil.html>. Acesso em: 17 fev. 2012.

FACEBOOK. Configurações de privacidade. Disponível em:

<http://www.facebook.com/settings/?tab=privacy\&ref=mb>. Acessado em: 01 jan. 2011.

FOUCAULT, M. Ditos e escritos IV: estratégia, poder-saber. Org. Manoel Barros da Mota. Trad. Vera Lúcia A. Ribeiro. Rio de Janeiro: Forense Universitária, 2006.

FOUCAULT, M. Vigiar e punir. (1970-1975). Petrópolis, RJ: Vozes, 1987.

FOUCAULT, M. Microfísica do poder. Org. e trad. Roberto Machado. (17a ed.). Rio de Janeiro: Graal, 1979.

FREITAS, E. IPO do Facebook em Números. Site Administradores. 2012. Disponível em: <http://www.administradores.com.br/informe-se/infograficos/o-ipo-dofacebook-em-numeros/52407/>. Acesso em: 15 fev. 2012. 
GARCIA DOS SANTOS, L. Demasiadamente pós-humano. Entrevista. Novos estudos. - CEBRAP, São Paulo, n. 72, Julho 2005. Disponível em: $<$ http://www.scielo. br/scielo.php?script=sci_arttext\&pid=S010133002005000200009\&lng=en\&nrm=iso>. Acessado em: 27 fev. 2011.

GUIDDENS, A. As consequências da modernidade. São Paulo: Editora Estadual Paulista, 1991.

KARASINSKI, E. O que é geolocalização?. 2011. Disponível em: <http://www.baixaki.com.br/tecnologia/3659-o-que-e-geolocalizacao-.htm>. Acessado em:10 jan. 2011.

KAHNEY, L. A cabeça de Steve Jobs. Trad. de Maria Helena Lyra. Rio de Janeiro: Agir, 2008.

INFO ONLINE. Facebook cresce $\mathbf{2 5 8} \%$ no Brasil em 2010. Caderno de Internet. Jor. Cauã Taborda. Disponível em:

<http://info.abril.com.br/noticias/internet/facebook-cresce-258-no-brasil-em-201010022011-42.shl>. Acessado em: 10 fev. 2011.

LÁZARO, A. S. Análise e seleção de algoritmos de filtragem de informação para solução do problema cold-start item. Lavras, MG: [s.n.], 2010.

LÉVY, P. O que é o virtual? São Paulo: Editora 34, 1996.

OAKESHOTT, M. Sobre o fato de ser conservador. In: CRESPIGNY, Anthony de (ed.). Ideologias políticas. $2^{\mathrm{a}}$ edição. Brasília: Ed. Universidade de Brasília, 1999.

SASSEN, S. The global city: New York, London, Tokyo. Princeton: Princeton University Press, 1991.

SCHEIBE, L. F. Desenvolvimento sustentável, desenvolvimento durável.

Subsídio de aula do Doutorado Interdisciplinar em Ciências Humanas. Florianópolis, SC: [s.n.], 2010.

SIBILIA, P. Celebridade para todos: um antídoto contra a solidão? Cienc. Cult. [online]. 2010, v. 62, n. 2. pp. 38-44. Disponível em: 
<http://cienciaecultura.bvs.br/scielo.php?script=sci_arttext\&pid=S000967252010000200022\&lng=en\&nrm=iso>. Acessado em: 27 fev. 2011.

SIBILIA, P. Sociedade do espetáculo: só é o que se vê. Entrevista por Patricia Fachin. HU Online. 2010a. Disponível em: < http://www.unisinos.br/ihu>. Acessado em: 27 jan. 2011.

SIBILIA, P. O show do eu: a intimidade como espetáculo. Rio de Janeiro: Nova Fronteira, 2008.

TODOROV, T. A vida em comum. Campinas: Papirus, 1996.

UIT (União Internacional de Telecomunicações). Celular chegará a dois terços da população. O Estado de São Paulo, 2010. Disponível em:

<http://www.estadao.com.br/estadaodehoje/20101020/not_imp627099,0.php>. Acessado em: 20 out. 2010.

VALLS, C. A revolução do Facebook Places, o geolocalizador da maior rede do mundo. 2010. Disponível em: <http://claudiavalls.wordpress.com/2010/11/07/arevolucao-do-facebook-places-o-geolocalizador-da-maior-rede-do-mundo/>. Acessado em: 07 nov. 2010.

ZIZEK, S. A visão em paralaxe. Trad. M. B. de Medina. São Paulo: Boitempo, 2008.

Artigo:

Recebido em: 13/04/2012

Aceito em: $29 / 07 / 2012$ 